\title{
Tecnologias na educação: Utilização do software de autoria Hot Potatoes na aprendizagem de geografia
}

\author{
Luiz de S. Santos ${ }^{1}$, Nívia L. Santos ${ }^{1}$, Daniele P. Noronha ${ }^{1}$, Janemar Hounsell ${ }^{2}$ \\ ${ }^{1}$ Escola Superior de Tecnologia (EST) - Universidade do Estado do Amazonas (UEA) \\ Av. Darcy Vargas, 1200 - Parque 10, Manaus - AM, 69065-020. \\ ${ }^{2}$ Escola Municipal Ana Mota Braga - 69067-530 - Manaus - AM - Brasil \\ \{luss.inf, nls.inf, dpnoronha\}@uea.edu.br, janemarhounsell@gmail.com
}

\begin{abstract}
This article presents the use of educational technology to promote an innovative teaching through activities carried out by PIBID scholarship holders (Institutional Program of the Initiation to Teaching Scholarship) belonging to the course of Licenciatura in Computing applied in a municipal public elementary school, Inserting the authoring software hot potatoes as a didactic tool in the content climates and biomes of the geography discipline. The objective was to promote a construction of activities through the software so that the students can better understand the subject addressed in the room. Exploratory research counted on the participation of 28 students from 11 to 13 years old. Data collection was done through a test and questionnaire applied to students before and after the application of the software.
\end{abstract}

Keywords: computing, construction, teaching, didactics

RESUMO: Este artigo apresenta o uso de tecnologia educativa visando promover um ensino inovador através de atividades realizadas pelos bolsistas do PIBID - Programa Institucional de Bolsa de Iniciação à Docência do curso de Licenciatura em Computação aplicado numa escola pública municipal de ensino fundamental, inserindo o software de autoria hot potatoes como ferramenta didática no conteúdo climas e biomas da disciplina de geografia. O objetivo foi promover uma construção de atividades através do software de modo que os alunos possam compreender melhor o assunto abordado em sala. A pesquisa de caráter exploratório contou com a participação de 28 alunos de 11 a 13 anos. A coleta de dados foi feita através de teste e questionário aplicado aos estudantes antes e depois da aplicação do software.

Palavras-chave: computação, construção, ensino, didática

\section{Introdução}

Atualmente, a tecnologia está presente em praticamente todos os setores da sociedade. Empresas, escritórios, no trânsito, nos meios de transporte, na agricultura e em diversos outros segmentos da sociedade o ser humano faz uso dos recursos advindos da tecnologia para aprimorar e agilizar seus processos. 
Na educação, o uso da tecnologia como apoio as atividades pedagógicas é muito discutido. As universidades são as instituições que mais utilizam a tecnologia no seu processo de ensino e aprendizagem. Segundo Moran (2012), com a tecnologia as universidades têm aumentado os seus territórios, indo principalmente para o mundo virtual. Desta maneira, propor a inserção de softwares educacionais como estratégia didática também no ensino básico resulta em um ensino inovador que proporciona benefícios tanto para o professor quanto para o aluno e enriquece a interação aluno e colegas de classe, bem como fortalece a relação professor e aluno.

$\mathrm{Na}$ visão construcionista de Papert, o educador tem papel de mediador do conhecimento e deve permitir que o aluno construa o seu próprio aprendizado. Bastos (2010) afirma que neste contexto o professor deixa de ser o detentor de todo o conhecimento e torna-se mediador. Neste contexto, os software de autoria mostram-se alternativas viáveis para o desenvolvimento de atividades pedagógicas em sala de aula. Os professores, por sua vez, precisam utilizá-los de maneira adequada, explorando seus recursos de maneira eficaz para promover melhorias em suas aulas.

Por outro lado, grande parte dos professores não estão familiarizados com software e seus recursos, dificultando a implantação dos mesmos em suas aulas. Assim, destaca-se a importância da presença do licenciado em computação nas escolas, auxiliando os docentes quanto ao uso de tecnologias educacionais que poderão contribuir de maneira positiva em suas aulas. Segundo Santos (2016), o licenciado em computação é um profissional que tem grande entendimento da didática em sala de aula e também do funcionamento técnico das tecnologias educacionais, sendo sua presença de grande importância na hora de inserir tecnologias em sala de aula.

Neste cenário de inserção de tecnologias em sala de aula, este artigo apresenta um trabalho baseado nas ideias do construcionismo, em que o estudante participa como sujeito ativo na construção do seu próprio aprendizado por meio da experimentação, da pesquisa em grupo, do estimulo a dúvida e do desenvolvimento do raciocínio, entre outros procedimentos. Desta forma, a partir de sua ação, ele vai estabelecendo as propriedades dos objetos e construindo as características do mundo (PAPERT, 2008).

Partindo da hipótese "poderia a produção de atividades educativas no software Hot Potatoes potencializar o rendimento no ensino de geografia no ensino fundamental", este artigo tem por objetivo analisar o impacto da construção de atividades pelos estudantes do $6^{\circ}$ ano na disciplina de geografia. Este trabalho está dividido em 5 sessões. A segunda seção trata-se da contextualização, que traz as referências que embasam a realização deste trabalho; na terceira seção trata-se dos materiais e métodos utilizados na aplicação da atividade; na quarta seção são mostrados os resultados alcançados e a discussão dos mesmos; e, por fim, na quinta seção são mostradas a conclusões a respeito do trabalho realizado.

\section{Contextualização}

\subsection{Construcionismo e o software Hot Potatoes}

Este artigo teve como proposta a construção de atividades educacionais no software Hot Potatoes pelos estudantes, e sua aplicação encontra terreno fértil na teoria pedagógica construcionista, defendida por Seymour Papert (1994). Seguindo as ideias defendidas no Construcionismo, o trabalho desenvolvido teve como objetivo a construção de atividades educacionais no software pelos estudantes para promover o aprendizado e, 
consequentemente, melhorar o rendimento da turma na disciplina de geografia. Segundo Valente (1993), na proposta construcionista, o estudante constrói algo, ou seja, aprende "colocando a mão na massa".

O Construcionismo tem como base o construtivismo de Jean Piaget. Papert segue a mesma linha de pensamento de Piaget (1976), na qual a criança é vista como um ser que pensa e que pode construir a sua própria estrutura cognitiva, sem necessariamente ser ensinada. Bastos (2010) afirma que a diferença entre Construcionismo e Construtivismo está no fato de o primeiro utilizar a produção de objetos reais usando o computador para a construção do conhecimento.

Associando o conteúdo da disciplina visto em sala de aula as atividades construídas no software pelos alunos, outro aspecto positivo que a proposta buscou promover foi motivação dos estudantes em participar de maneira mais ativa nas aulas. Valente (1993) afirma que o fato de estar construindo algo que lhe interesse faz com que o estudante fique mais motivado.

Além disso, a aplicação das atividades descritas neste artigo favoreceu a interação dos estudantes com os conteúdos da disciplina, os quais foram utilizados no desenvolvimento das atividades no software. Papert (1980) defende que a interação favorece a construção do seu conhecimento.

Aliado aos princípios do Construcionismo, o trabalho desenvolvido teve como foco principal a construção de atividades no Hot Potatoes, que é uma ferramenta de autoria canadense que disponibiliza 5 possibilidades de atividades educativas a serem trabalhadas pelos professores. Leffa (2006) afirma que ferramentas de autoria são software que são usados na produção de arquivos digitais multimídia, sem a necessidade de o autor saber programar em uma linguagem de programação. Ele foi desenvolvido para ser utilizado por professores, porém na atividade desenvolvida, os estudantes produziram as atividades, seguindo a proposta construcionista. Dessa maneira, o papel do professor da disciplina e dos licenciados em computação na produção das atividades foi o de facilitador, sendo o estudante a figura principal no desenvolvimento das atividades.

\section{Materiais e métodos}

O presente estudo tem como característica uma pesquisa experimental embasada na análise estatística descritiva. A pesquisa realizada tem natureza exploratória, podendo o pesquisador manipular o comportamento direto, precisa e sistematicamente tendo como base observações direta e aplicação de questionários estruturados que resulta numa pesquisa quali-quantitativa que aborda conceitos e dados qualitativos aliados aos dados quantitativos (YIN, 2010).

O local escolhido para a realização do estudo foi a Escola Municipal Ana Mota Braga e contou com a participação da turma do $6^{\circ}$. Foi utilizada na execução das atividades a sala de aula e o laboratório de informática, que apresenta 10 computadores e projetor- multimídia.

Nas análises em sala de aula foi constatado que a professora apenas utiliza o livro como recurso didático, mas os estudantes não apresentam interesse em compreender o assunto. Diante disso foi aplicado um questionário de questões de múltipla escolha relacionado as tecnologias que estão disponíveis aos estudantes em seu 
cotidiano, bem como o uso da internet e um pré-teste para averiguar o nível de conhecimento adquirido pelos estudantes acerca do conteúdo climas e biomas.

A unidade amostral é composta por 28 alunos com idades entre 12 e 13 anos, sendo $46 \%$ do sexo feminino e $54 \%$ do sexo masculino.

O início do trabalho se deu com a escolha da metodologia que iria se adotar no desenvolvimento da atividade. Assim, optou-se pelo desenvolvimento de objetos de aprendizagem utilizando uma ferramenta de autoria. A proposta consistia em fazer com que os estudantes interagissem com a ferramenta e, após o contato com a mesma, desenvolvessem seus próprios projetos baseados nos conteúdos vistos em sala de aula. O software escolhido para o desenvolvimento dos objetos de aprendizagem foi o Hot Potatoes, uma ferramenta desenvolvida que permite a criação cinco tipos de atividades educacionais, como palavras cruzadas, quiz, preenchimento de lacunas, exercícios de ordenação de pares e ordenação de frases. Há ainda uma sexta função que permite que todas as atividades possam ser colocadas em um único arquivo.

A escolha da ferramenta se deu por fatores como o custo na utilização da ferramenta, visto que ela possui versão grátis; o fácil acesso, pois a ferramenta se encontrava devidamente instalado em todos os computadores do laboratório utilizado na aplicação; a sua fácil manipulação, que não exige muito esforço para o aprendizado de suas funções; e a compatibilidade dos objetos produzidos nele, já que o resultado das atividades produzidas são documentos HTML. Desta forma, os estudantes poderiam visualizar seus projetos prontos de qualquer computador independente do sistema operacional que utilizassem.

A proposta, assim como a ferramenta, foi apresentada ao professor de geografia e aos alunos em sala de aula, que logo depois foram divididos em grupos de até 4 componentes. Após a formação dos grupos, deu-se início a primeira etapa da aplicação, que consistiu na elaboração do story board da atividade, na qual os estudantes, dispostos na sala de aula em grupo, criaram as atividades, como as palavras cruzadas e o quiz, utilizando papel, lápis e/ou caneta, dispensando o uso do computador. O livro didático auxiliou os estudantes na elaboração de atividades que contextualizassem com os conteúdos apresentados em sala de aula.

Concluída a etapa de story board, os estudantes foram levados ao laboratório de informática para que confeccionassem suas atividades utilizando o software Hot Potatoes. Nesta etapa, primeiramente, foram apresentados alguns recursos do software que poderiam ser utilizados em suas criações, tais como criação de quiz, palavras cruzadas, geração automáticas de grades nas palavras cruzadas, definição das respostas corretas, feedback ao usuário quando respondesse de maneira correta e também de maneira errada, entre outros.

A primeira atividade trabalhada foram palavras cruzadas. Em seguida foi o preenchimento de lacunas e, por fim, a confecção do quiz. Durante a construção de todas essas atividades, eram abordadas primeiramente seus recursos e possibilidades e em seguida os estudantes faziam uso das ferramentas apresentadas para construírem suas atividades. 
VI Congresso Brasileiro de Informática na Educação (CBIE 2017)

Anais do XXIII Workshop de Informática na Escola (WIE 2017)

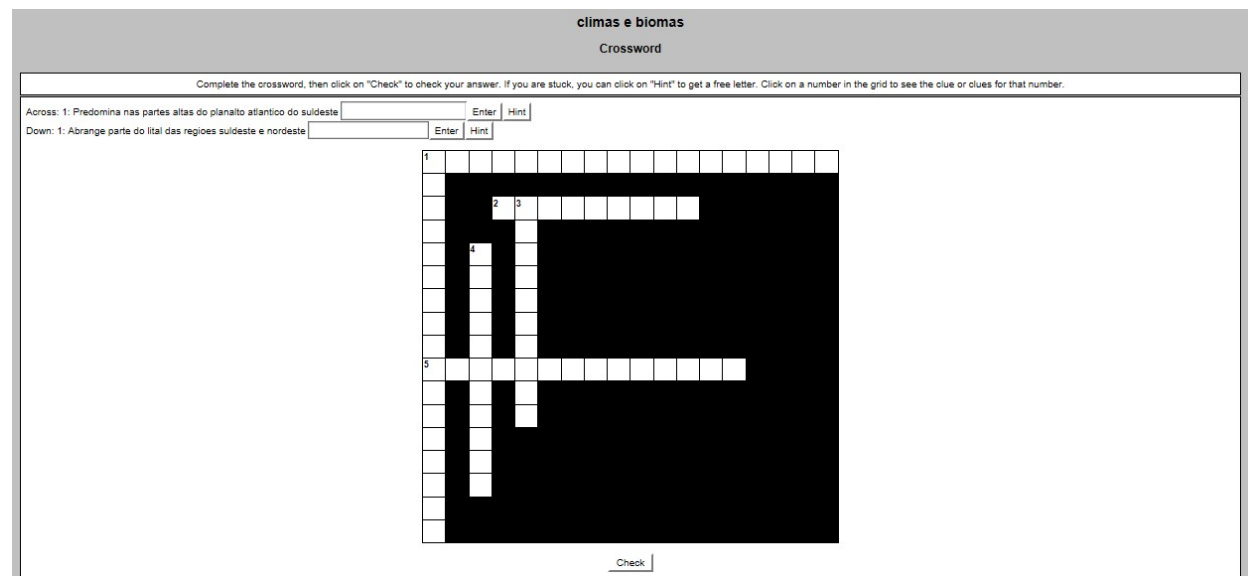

Figura 1. Atividade de palavras cruzadas desenvolvida pelos estudantes. Fonte: autores

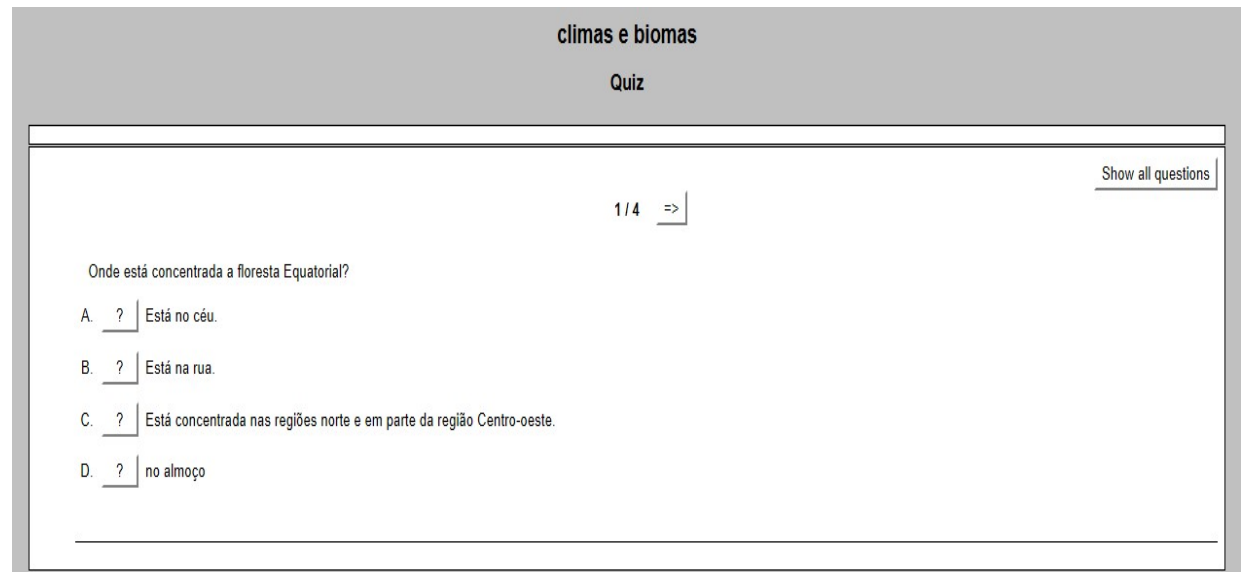

Figura 2. Quiz desenvolvido pelos estudantes. Fonte: autores

Por fim cada equipe apresentou suas criações para a turma, que pode interagir com as atividades criadas, e para o professor, em seguida a turma respondeu o pós-teste sobre o conteúdo e um teste de satisfação quanto ao uso da ferramenta.

\section{Resultados e discussão}

O impacto da atividade desenvolvida foi medido através de avaliação somativa da aprendizagem dos estudantes, com objetivo de responder a seguinte questão: a construção de atividades educativas em um software de autoria com a turma do $6^{\circ}$ ano influencia o rendimento dos estudantes na disciplina de geografia? Isso nos leva as seguintes hipóteses:

- H1-0: A produção de atividades educativas no software hot Potatoes não potencializa o rendimento na aprendizagem de geografia no ensino fundamental.

- H1-1: A produção de atividades educativas no software hot Potatoes potencializa o rendimento na aprendizagem de geografia no ensino fundamental. 
VI Congresso Brasileiro de Informática na Educação (CBIE 2017)

Anais do XXIII Workshop de Informática na Escola (WIE 2017)

As duas hipóteses descritas podem ser definidas conforma mostra a Tabela 1, onde $\mathrm{M}$ representa a média de rendimento do grupo de alunos, SEA representa Software Educacional Ativado e SED representa Software Educacional Desativado.

Tabela 1.Definição das variáveis

\begin{tabular}{c|c|c}
\hline Hipótese & Hipótese Nula & Hipótese Alternativa \\
\hline H1 & H1.0:M(SEA $)=\mathrm{M}(\mathrm{SED})$ & $\mathrm{H} 1.1: \mathrm{M}(\mathrm{SEA}) \neq \mathrm{M}(\mathrm{SED})$ \\
\hline
\end{tabular}

Como resultados do questionário socioeconômico aplicado com a turma foi possível obter detalhes do perfil tecnológico da turma. Constatou-se que a maioria dos estudantes possui acesso ao computador e, principalmente, ao smarthphone, como mostrado nos gráficos 1 e 2. Em relação ao acesso à Internet, conforme mostrado no gráfico 3, 100\% da turma diz possuir acesso à Internet para jogos, redes sociais e pesquisa para trabalhos escolares. Por meio desses dados, pode-se inferir que a turma possui familiaridade com recursos tecnológicos, o que torna a implantação de recursos tecnológicos viável nas atividades escolares da turma.

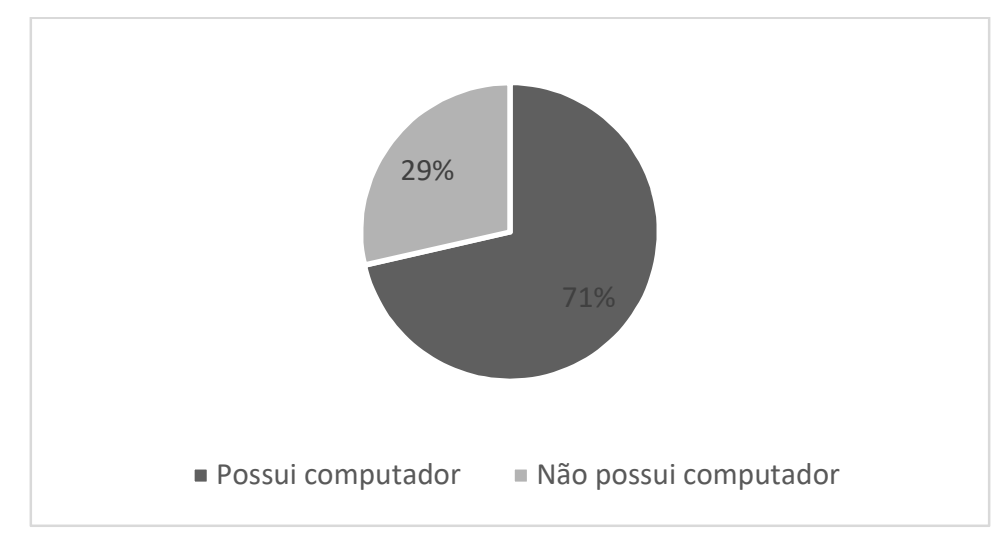

Gráfico 1. Acesso ao computador

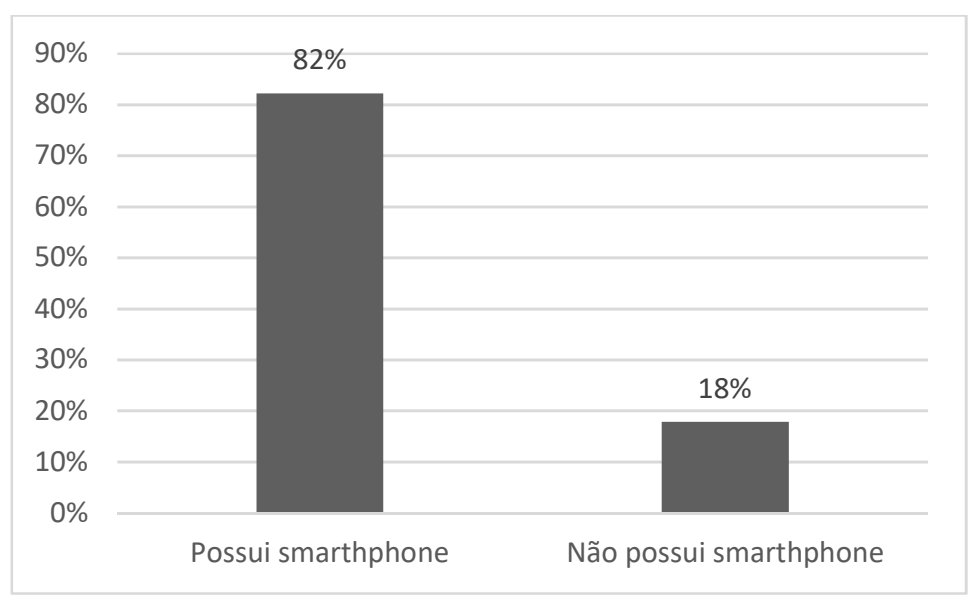

Gráfico 2. Acesso ao smarthphone 
VI Congresso Brasileiro de Informática na Educação (CBIE 2017)

Anais do XXIII Workshop de Informática na Escola (WIE 2017)

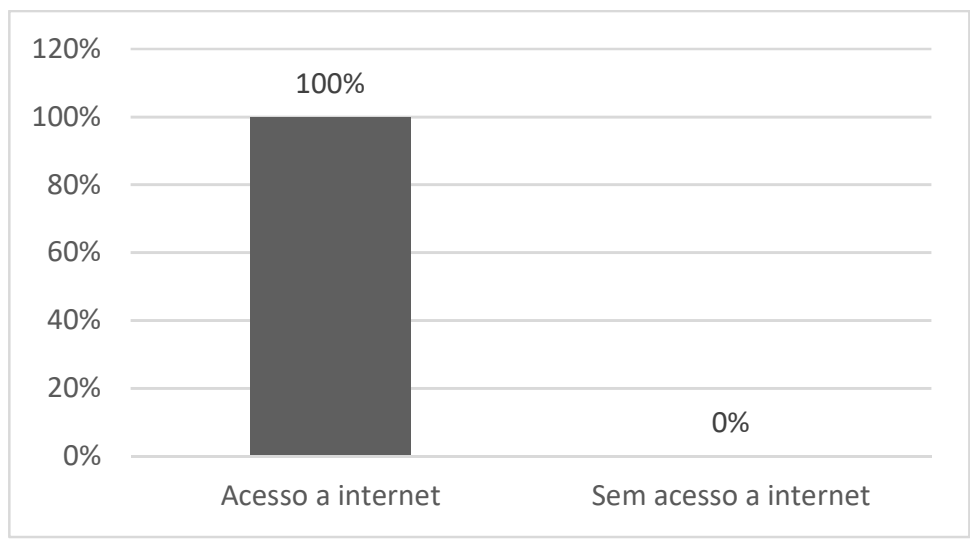

Gráfico 3. Acesso à internet

Como pré-teste foi realizada uma avaliação contendo 10 questões de múltipla escolha sobre o assunto abordado. O resultado deste teste foi uma média de 2,25 pontos em uma prova que tinha como nota máxima 10 pontos. Este resultado levou a pensar uma maneira de elevar o desempenho dos estudantes em sala de aula.

Após a aplicação das atividades propostas neste artigo (elaboração, construção de exercícios no software e apresentação das atividades criadas) em sala de aula, os estudantes conseguiram elevar a média da turma para 4,86 pontos, caracterizando uma melhoria no rendimento dos estudantes, conforme mostrado nos gráficos 4 e 5 , este último demonstrando a evolução da hipótese.

Afim de garantir a privacidade e o anonimato dos estudantes que participaram do experimento, foram removidas informações que poderiam identificar os participantes. A Tabela 1 mostra o rendimento dos 28 participantes nas duas avaliações para cada aluno com o intuito de identificar ao final os seus respectivos rendimentos.

Tabela 1. Desempenho individual

\begin{tabular}{|c|c|c|c|}
\hline Estudante & $\begin{array}{c}\text { Software } \\
\text { educacional } \\
\text { (desativado) }\end{array}$ & $\begin{array}{c}\text { Software } \\
\text { educacional } \\
\text { (ativado) }\end{array}$ & \% \\
\hline Aluno 1 & 2 & 7 & $50 \%$ \\
\hline Aluno 2 & 4 & 2 & $-20 \%$ \\
\hline Aluno 3 & 2 & 5 & $30 \%$ \\
\hline Aluno 4 & 2 & 4 & $20 \%$ \\
\hline Aluno 5 & 4 & 3 & $-10 \%$ \\
\hline Aluno 6 & 2 & 6 & $40 \%$ \\
\hline Aluno 7 & 3 & 8 & $50 \%$ \\
\hline Aluno 8 & 2 & 4 & $20 \%$ \\
\hline Aluno 9 & 1 & 4 & $30 \%$ \\
\hline Aluno 10 & 1 & 5 & $40 \%$ \\
\hline Aluno 11 & 6 & 8 & $20 \%$ \\
\hline Aluno 12 & 0 & 5 & $50 \%$ \\
\hline
\end{tabular}


VI Congresso Brasileiro de Informática na Educação (CBIE 2017)

Anais do XXIII Workshop de Informática na Escola (WIE 2017)

\begin{tabular}{|c|c|c|c|}
\hline Aluno 13 & 4 & 6 & $20 \%$ \\
\hline Aluno 14 & 1 & 4 & $30 \%$ \\
\hline Aluno 15 & 1 & 3 & $20 \%$ \\
\hline Aluno 16 & 2 & 1 & $-10 \%$ \\
\hline Aluno 17 & 4 & 4 & $0 \%$ \\
\hline Aluno 18 & 2 & 8 & $60 \%$ \\
\hline Aluno 19 & 1 & 4 & $30 \%$ \\
\hline Aluno 20 & 1 & 3 & $20 \%$ \\
\hline Aluno 21 & 3 & 8 & $50 \%$ \\
\hline Aluno 22 & 2 & 5 & $30 \%$ \\
\hline Aluno 23 & 1 & 4 & $30 \%$ \\
\hline Aluno 24 & 2 & 6 & $40 \%$ \\
\hline Aluno 25 & 1 & 3 & $20 \%$ \\
\hline Aluno 26 & 4 & 5 & $10 \%$ \\
\hline Aluno 27 & 1 & 4 & $30 \%$ \\
\hline Aluno 28 & 4 & 7 & $30 \%$ \\
\hline
\end{tabular}

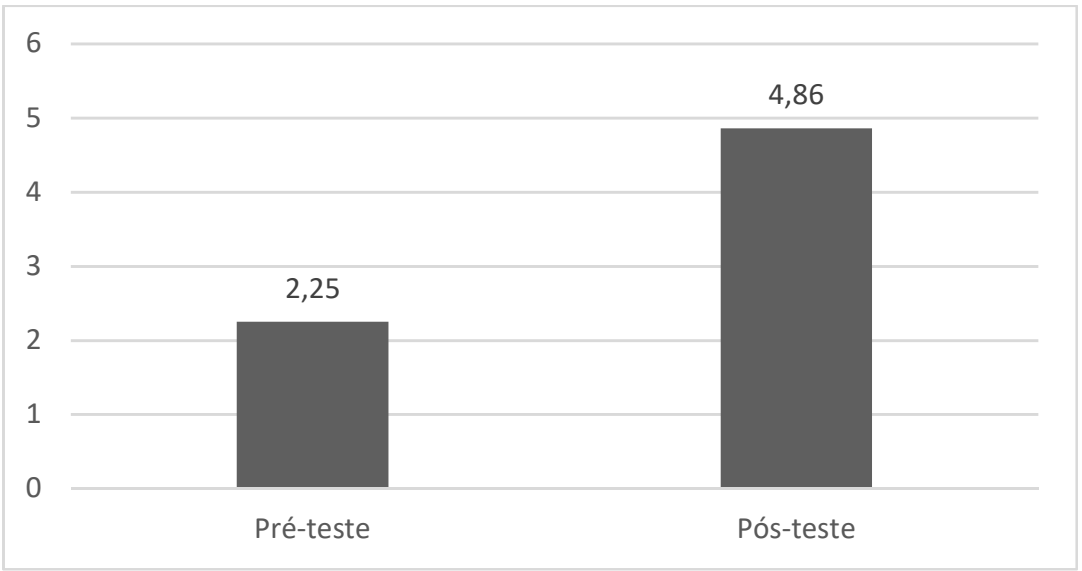

Gráfico 4. Médias 
VI Congresso Brasileiro de Informática na Educação (CBIE 2017)

Anais do XXIII Workshop de Informática na Escola (WIE 2017)

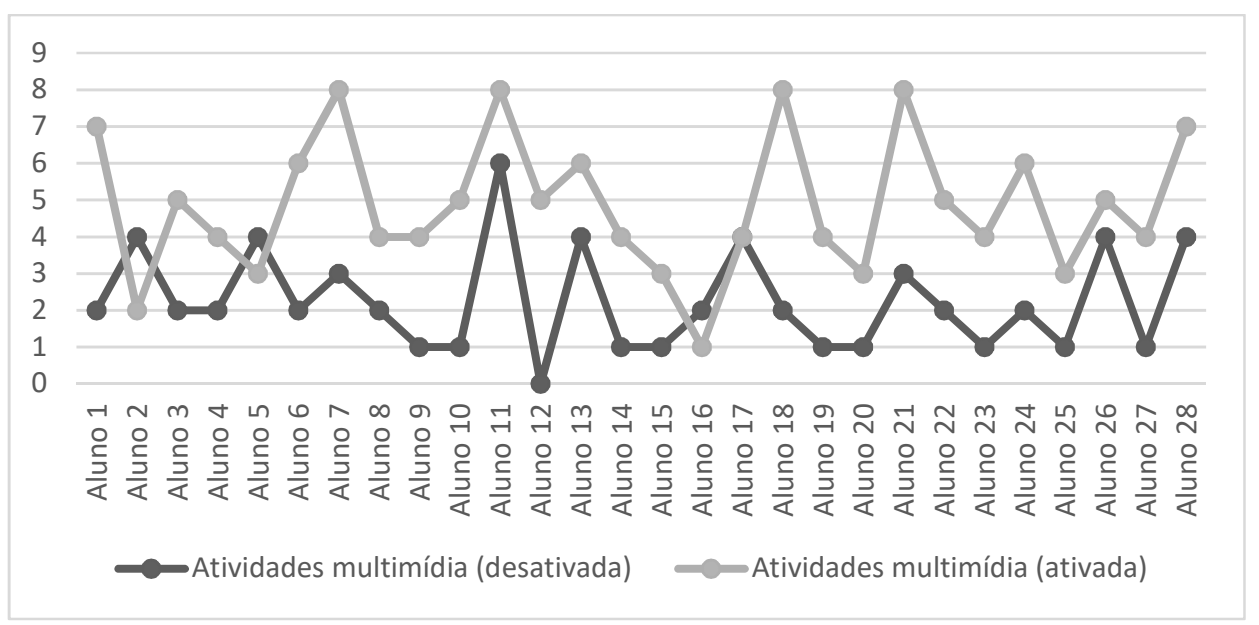

Gráfico 5. Evolução da hipótese

E ainda, por meio do resultado do teste $\mathrm{t}$ uni-caudal a direita, no qual Stat $\mathrm{t}>\mathrm{t}$ crítico $(3,24>1,67)$, rejeita-se $\mathrm{H} 0$ ao nível de $5 \%$ de significância, conforme mostrado na tabela 2. Dessa forma, pode-se dizer que houve uma melhora no rendimento dos estudantes após a construção das atividades no software Hot Potatoes.

Tabela 2. Resultados do teste T-Student

\begin{tabular}{|l|r|r|}
\hline & $\begin{array}{c}\text { Software } \\
\text { Educacional Ativado }\end{array}$ & $\begin{array}{c}\text { Software Educacional } \\
\text { Desativado }\end{array}$ \\
\hline Média & 4,857142857 & 2,25 \\
\hline Variância & 3,534391534 & 2,97222222 \\
\hline Observações & 28 & 28 \\
\hline Variância agrupada & 0 & \\
\hline Hipótese da diferença de média & 54 & \\
\hline Gl & 2,753306878 & \\
\hline Stat $\mathrm{t}$ & 5,878973963 & \\
\hline $\mathrm{P}(\mathrm{T}<=\mathrm{t})$ uni-caudal & $1,3321 \mathrm{E}-07$ & \\
\hline $\mathrm{t}$ crítico uni-caudal & 1,673564906 & \\
\hline $\mathrm{P}(\mathrm{T}<=\mathrm{t})$ bi-caudal & $2,66421 \mathrm{E}-07$ & \\
\hline $\mathrm{t}$ crítico bi-caudal & 2,004879288 & \\
\hline
\end{tabular}

Além disso, foi aplicado um questionário de satisfação aos alunos visando obter sua opinião acerca do uso do software nas aulas de geografia, na qual pode se constatar que $92,9 \%$ dos alunos gostaram de usar a ferramenta e 78,6\% acharam-na fácil de ser usada.

Diante dos resultados obtidos, é possível afirmar que a atividade provocou um impacto positivo em sala de aula, alcançando um aumento de cerca de $26 \%$ no rendimento dos estudantes na disciplina.

\section{Conclusões}

Por meio dos resultados obtidos, pode-se concluir que um ensino inovador, no qual os professores usam softwares educacionais para que seus alunos possam interagir com o 
conteúdo, pode resultar num bom rendimento em sala de aula, proporcionando melhorias na aprendizagem. Contudo, é de suma importância que o professor planeje de maneira adequada as atividades em sala de aula, domine as funcionalidades do software e/ou recurso a ser utilizado, ou que busque auxílio de outros profissionais, como o licenciado em computação, na implantação de ferramentas tecnológicas em sala de aula.

Os resultados deste trabalho, demonstram ainda que, quando passamos as responsabilidades de construção de atividades para os alunos, seu engajamento aumenta de forma a possibilitar uma construção de conhecimento que fará parte do seu cotidiano e o contato dos alunos com os software educacionais possibilita a ampliação do interesse dos estudantes. Em trabalhos futuros pode-se haver melhorias nos métodos utilizados e ampliação da unidade experimental, uma vez que o experimento foi realizado com apenas uma turma, buscando retratar melhor o impacto do uso de software na aprendizagem dos estudantes.

\section{Referências}

Bastos, B. L., Borges, M., \& D'Abreu, J. (2010). Scratch, Arduino e o Construcionismo: ferramentas para a educação. Seminário de Tecnologia Educacional de Araucária.

Brasil, Secretaria de Educação Fundamental do (1997). Parâmetros Curriculares Nacionais: introdução. 3.ed. Brasília: MEC, vol 1.

Leffa, V. J. (2006). Uma ferramenta de autoria para o professor: o que é e o que faz. Porto Alegre, Letras de Hoje.

Mayer, R. E. (2009). Teoria Cognitiva da Aprendizagem Multimédia. In G. L. Miranda (Ed.), Ensino online e aprendizagem multimédia (pp. 207-237). Lisboa: Relógio D'Água.

Moran, J. M. (2007). A educação que desejamos: novos desafios e como chegar lá. Papirus Editora.

Papert, S. (2008). A máquina das crianças: repensando a escola na era da informática. Artmed.

SBC. Sociedade Brasileira de Computação (2002). Currículo de Referência para Cursos de Licenciatura em Computação. Disponível em: <http://www.sbc.org.br>. Acesso em: 18 de Jun. 2016.

Santos, N. L, Santos, L. S, Hounsell, J., Noronha, D.P. (2016). Softwares educacionais: $\mathrm{O}$ papel do licenciado em computação na escola. In: Anais do V Congresso Brasileiro da Sociedade Brasileira de Computação (Mostra Prática de Informática na Educação). Uberlândia: SBC.

Valente, José Armando (1993). "Por Quê O Computador Na Educação?" In Computadores E Conhecimento: Repensando a Educação. Unicamp/Nied.

Yin, R. K. (2010). Estudo de caso: planejamento e métodos. 4. ed. Porto Alegre. 